\title{
Aerial surveys to monitor bluefin tuna abundance and track efficiency of management measures
}

\author{
Robert Klaus Bauer, Sylvain Bonhommeau, Blandine Brisset, Jean-Marc Fromentin* \\ IFREMER, UMR Marbec, Avenue Jean Monnet, CS 30171, 34203 Sète Cedex, France
}

\begin{abstract}
Conservation and management measures for exploited fish species rely on our ability to monitor variations in population abundance. In the case of the eastern stock of Atlantic bluefin tuna (ABFT), recent changes in management policies have strongly affected the reliability of fishery-dependent indicators due to drastic changes in fishing season/area, fisheries selectivity and strategy. However, fishery-independent indices of abundance are rare for large pelagic fish, and obtaining them is often costly and labor intensive. Here, we show that scientific aerial surveys are an appropriate tool for monitoring juvenile bluefin tuna abundance in the Mediterranean. We present an abundance index based on 62 aerial surveys conducted since 2000, using 2 statistical approaches to deal with the sampling strategy: line and strip transects. Both approaches showed a significant increase in juvenile ABFT abundance in recent years, resulting from the recovery plan established in 2007. Nonetheless, the estimates from the line transect method appear to be more robust and stable. This study provides essential information for fisheries management. Expanding the spatial coverage to other nursery grounds would further increase the reliability and representativeness of this index.
\end{abstract}

KEY WORDS: Thunnus thynnus - Index of abundance - Fishery-independent - Gulf of Lions · Mediterranean Sea $\cdot$ Strip transect $\cdot$ Distance sampling

Resale or republication not permitted without written consent of the publisher

\section{INTRODUCTION}

Declines in the Atlantic bluefin tuna Thunnus thynnus (ABFT) stocks, mostly resulting from extensive over-fishing, have been widely publicized in recent decades. The overexploitation of this species has been driven by both high fishing pressure and failure of management regulations (Fromentin et al. 2014). To counteract this trend, a multi-annual stock recovery plan was implemented in 2007 by the International Commission for the Conservation of Atlantic Tunas (ICCAT). This plan included significant restrictions of the fishing season and, later, on the quotas and minimum landing size as well as a significant reinforcement of the control of fishing activity (ICCAT 2006). These measures have had considerable impacts on the spatial patterns of tuna fleets and thus compromised the reliability of fisheries-derived abundance indices, in particular catch per unit effort (CPUE), used to mon- itor changes in the stock. Fisheries-independent information is thus essential to overcome this uncertainty. Tagging programs as well as larval and acoustic surveys can provide such information but are constrained by high costs and effort resulting from the broad scale at which they need to be implemented (Josse et al. 2000, Hobday et al. 2009, Fujioka et al. 2010, Ingram et al. 2013, Leroy et al. 2015). These methods are also yet to be fully integrated into the assessment models, particularly movement and stock composition. An alternative and more effective source could be the use of aerial surveys to obtain tuna school counts (Polacheck et al. 1998). In fact, spotter aircrafts have been used for a long time in purse seine fisheries to assist in locating tuna schools (e.g. since 1974 in the Mediterranean; Petit et al. 1990), and their efficiency has previously been demonstrated (Scott \& Flittner 1972).

The use of aerial surveys for estimating animal densities has a long tradition in wildlife research and 
management (Buckland 2001), and such surveys are increasingly applied to marine organisms (e.g. sea turtles and marine mammals; Lauriano et al. 2011, Panigada et al. 2011, Alves et al. 2013). There is a growing interest in the potential use of aerial surveys for tuna stock assessment (Hoggard 1995, Polacheck et al. 1998, Lutcavage \& Newlands 1999, Natale 2011). Promising results have been obtained from aerial surveys on juvenile Southern bluefin tuna Thunnus maccoyii (age 2 to 4,8 to $30 \mathrm{~kg}$ ) in the Great Australian Bight that are now used to construct an index of abundance (Eveson et al. 2012). In the case of ABFT, aerial surveys on mature individuals $(\sim 196 \mathrm{~cm},>226 \mathrm{~kg})$ have been conducted in the Gulf of Maine and along their migration pathways at the Great Bahama Banks, known as the 'Tuna Alley' (Hoggard 1995, Lutcavage \& Kraus 1997, Lutcavage \& Newlands 1999, Newlands et al. 2006). However, the majority of these operations were performed using commercial spotter pilots and lacked a rigorous statistical sampling design.

In this study, we illustrate the results from aerial surveys conducted since 2000 on juvenile ABFT (70 to $115 \mathrm{~cm},<30 \mathrm{~kg}, 2$ to $4 \mathrm{yr}$ ) in the Gulf of Lions (GoL) (Bonhommeau et al. 2010, Fromentin et al. 2013). In order to monitor population fluctuation, it is crucial to assess juvenile abundance, in particular to rapidly assess the success of management measures or to identify effects caused by fisheries or environmental changes. In this regard, nursery grounds represent essential survey areas. The GoL, with its large shelf region and numerous canyons, represents one such area for ABFT (Farrugio 1977). This region is considered one of the most productive areas in the Mediterranean Sea, in contrast to the oligotrophic conditions typically encountered throughout this basin. Based on this dataset, we present an abundance index for juvenile ABFT in the northwestern Mediterranean Sea. Two competing statistical methods to derive density estimates from aerial surveys, the strip and line transect approaches -inconsistently applied by the scientific community-are evaluated and the required methodological adaptations for ABFT are discussed. Effects of recently implemented management measures on population trends are investigated.

\section{MATERIALS AND METHODS}

\section{Aerial surveys}

Aerial surveys of juvenile Atlantic bluefin tuna were carried out in the GoL over 2000 to 2003 and 2009 to present during August to October (Table 1;
Table 1. Overview of conducted tuna surveys per year and month. Effort measures represent the length of traveled transects

\begin{tabular}{|lccccc|}
\hline Year & $\begin{array}{c}\text { Effort } \\
\text { (km) }\end{array}$ & $\begin{array}{c}\text { Surveys with } \\
\text { no sightings } \\
\text { (\% effort) }\end{array}$ & \multicolumn{3}{c|}{$\begin{array}{c}\text { Surveys by month } \\
\text { (\% effort) }\end{array}$} \\
\hline 2000 & 3635 & 31.6 & 0 & 100 & 0 \\
2001 & 4869 & 37.3 & 14 & 76 & 10.8 \\
2002 & 5440 & 43.8 & 44 & 22 & 34.2 \\
2003 & 6791 & 9.8 & 54 & 46 & 0 \\
2009 & 4585 & 0 & 41 & 59 & 0 \\
2010 & 3123 & 16.8 & 21 & 40 & 38.2 \\
2011 & 5449 & 0 & 33 & 58 & 8.7 \\
2012 & 4713 & 0 & 22 & 21 & 56.8 \\
$2000-2012$ & 38606 & 16.9 & 31 & 51 & 17.4 \\
\hline
\end{tabular}

Bonhommeau et al. 2010, Fromentin et al. 2013). This period corresponded to the main fishing season in this area (Fromentin \& Powers 2005). Young bluefin tuna (here mostly ages 1 to 4 ) are easily detected by plane during feeding bouts when they swim or jump at the surface (Fig. 1; Scott \& Flittner 1972). Surveys were carried out at the same time of day (around noon when the sun is at its highest, to avoid sun glare) and only under favorable weather conditions, i.e. sunny sky and low wind speed $\left(<28 \mathrm{~km} \mathrm{~h}^{-1}\right)$. Surveys took place aboard a Cessna C 337 'Push Pull' from 2000 to 2011 and since 2012 aboard a Cessna $208 \mathrm{ISR}$, at 1000 and $1500 \mathrm{ft}$ (305 and $457 \mathrm{~m}$ ) above the sea level, respectively.

Tuna schools were spotted by 1 to 3 trained scientific observers, from both sides of the plane/transects, while the pilots provided supplementary sightings on the transect line. During each survey, a GPS recorded the position of the plane every $30 \mathrm{~s}$, while waypoints of sighted tuna schools were recorded manually by the observers (we usually used 2 GPS devices, onboard GPS and a manual device, Garmin GPS III PILOT). A standard survey consists of 10 vertical transects across the GoL region (Fig. 2), with a total length of $1120 \mathrm{~km}$ (including off-route effort), spaced by an inter-transect distance of $13.8 \mathrm{~km}$. At this distance, double counting of schools on subsequent transect lines due to tuna migrations is unlikely, because tunas are almost exclusively sighted feeding and not migrating (unlike in the Bahama banks, where ABFT are basically migrating at the surface). Furthermore, the use of the GPS allowed us to identify schools that had been already observed during the previous legs and thus avoid double counting if the school had remained roughly at the same place. All transects could be surveyed within $6 \mathrm{~h}$ at a constant speed of $200 \mathrm{~km} \mathrm{~h}^{-1}$ with the Cessna 


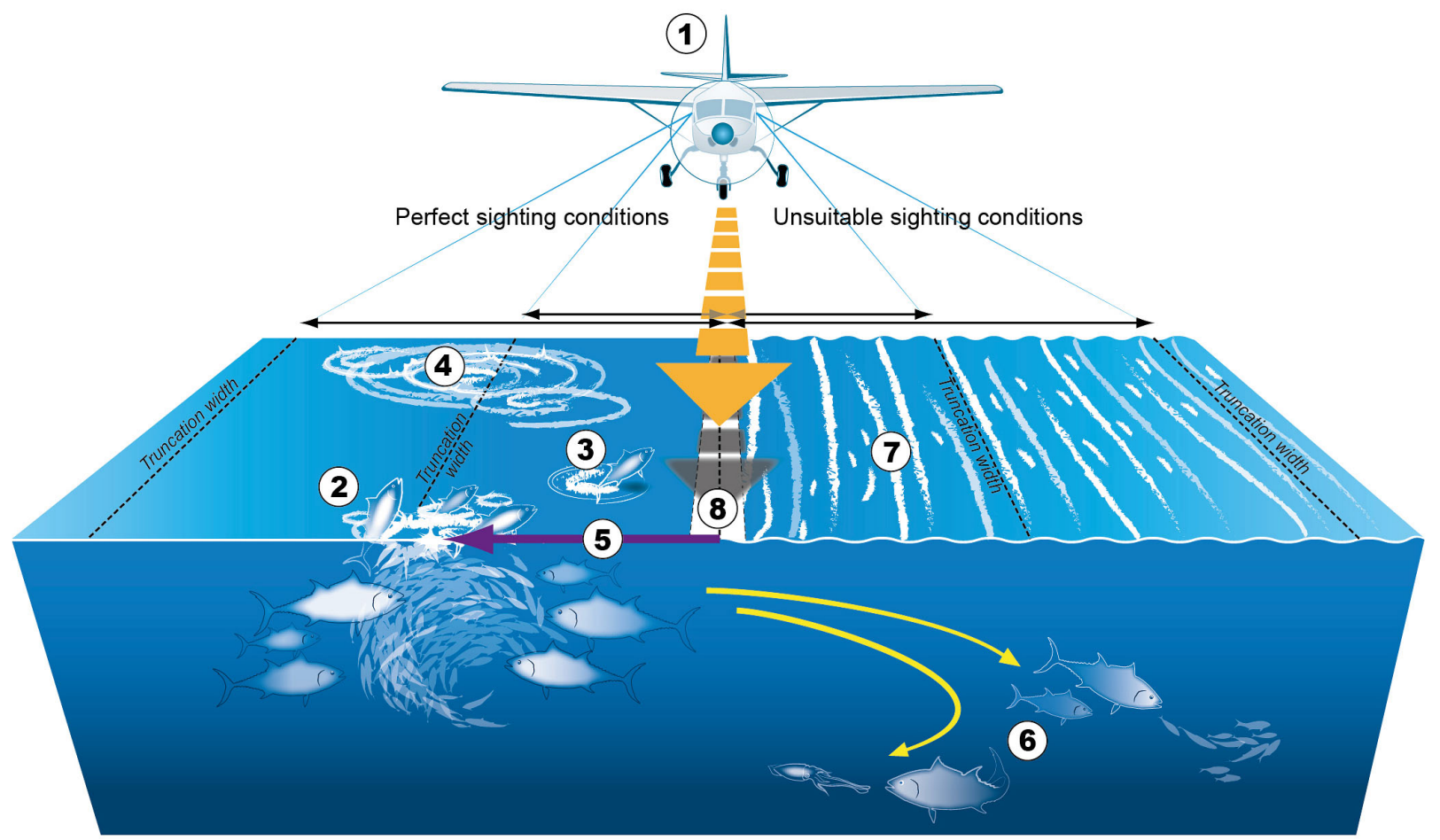

Fig. 1. Schematic drawing illustrating Atlantic bluefin tuna Thunnus thynnus aerial surveys under perfect (left side) and impaired (right side) survey conditions. (1) aircraft on transect line; (2) tuna school feeding with multiple jumpers; (3) small tuna school feeding with single tuna jumping; (4) large tuna school aggregation zones extending over several miles; (5) perpendicular distance; (6) tuna schools chasing in deeper waters; (7) waves with whitecaps; (8) blind spot for lateral detection

208 ISR (the duration of each cruise changing according to the number of sightings). The maximum possible distance that could be covered by the first plane (the Cessna C 337) was limited due to fuel tank capacity and required that the route be split into 2 parts, a western and an eastern component, divided around $4.58^{\circ} \mathrm{E}$. Both of these components were each surveyed within $4 \mathrm{~h}$ during different, usually subsequent, days. The aircraft change in 2012 allowed us also to georeference tuna schools directly from the transect line as well as to record the entire survey using a WESCAM MX-15HDi camera with built-in GPS. By contrast, during previous surveys conducted on board the Cessna C 337, position records were taken while circling above spotted schools, which required the plane to leave and return to the transect line. Another, more common sampling practice in aerial surveys, where the positions of sighted objects are not directly measured, is to back-calculate perpendicular distances to sighted objects from sighting angles and the aircraft altitude (Beavers \& Ramsey 1998, Andriolo et al. 2006). Here, sighting angles are measured by an inclinometer while the object of interest is abeam the aircraft. As this method requires additional handling time by the observer, it was not applicable for our aerial surveys-conducted at a high traveling speed-where tuna schools could pass through the detection range in a few seconds, partly in swift succession. A comparison of the accuracy of both sampling methods is given by Marques et al. (2006). Sightings generally included

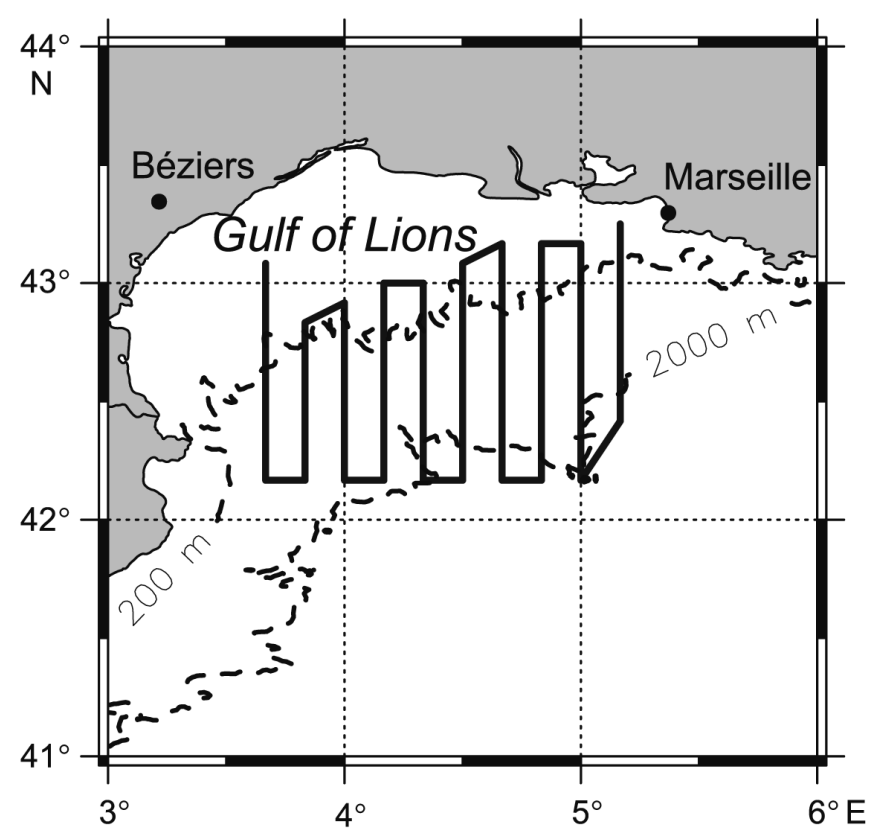

Fig. 2. Study area and transect lines of aerial surveys. The dashed lines represent the 200 and $2000 \mathrm{~m}$ isobaths, indicating the continental shelf break of the Gulf of Lions 
tuna schools of varying size feeding on small pelagic fish (e.g. anchovies or sardines) and which were regularly accompanied by sea birds and less often by whales, dolphins or other tuna species. Detected schools were hence classified by size, depending on the size of the produced surface disturbance ('small' for single to few individuals, 'medium' for several individuals and 'large' for a large area of surfacing and hunting tunas; Fig. 1, see Fig. S1 in the Supplement at www.int-res.com/articles/suppl/m534p221 _supp.pdf). In some cases, schools occurred in short succession, very close to each other, so that only 1 waypoint was taken for several schools. Since 2009, we encountered areas with numerous tuna schools. School counting in these areas was particularly difficult due to the high number and the dynamics of the schools (which appeared/disappeared rapidly). To describe these sightings, we created a new category ('aggregation zone'; Fig. 1). In addition to the position, number and size of tuna schools, the observers on board the aircraft and weather conditions (e.g. clouds, sea state) were recorded for each survey. Transect sections with heavy cloud cover or breaking waves were skipped and therefore discarded from subsequent analysis.

\section{Data analysis}

GPS allowed us to obtain accurate positions of the route and sightings and thus reliable perpendicular distances, which are crucial for distance sampling theory (Buckland 2001). The perpendicular distance is simply the shortest distance between the route and the spotted tuna school (Fig. 1). This distance is used as the input for subsequent analyses, the strip and line transect modeling (see below). Potential sources of errors in the calculation of perpendicular distances may include the precision at which transect routes are kept by the plane and the precision of school position records. To reduce bias caused by systematic route deviations, perpendicular distances were calculated based on actual plane and not on intended flight route tracks. For this purpose, sections with offroad trips, made until 2012 to take tuna school positions, were discarded and interpolated. Due to this sampling practice, the accuracy of related school positions was assessed. Since actual school positions were not available as reference points, it was assumed that the accuracy of position records may approximate the reaction time of observers, specifically, the distance traveled within this time. Assuming a reaction time of 1 or $2 \mathrm{~s}$ and an average plane speed of $56 \mathrm{~m} \mathrm{~s}^{-1}\left(200 \mathrm{~km} \mathrm{~h}^{-1}\right)$, the precision of position records made until 2012 could vary between 56 and $120 \mathrm{~m}$. By contrast, position records obtained since 2012 on board of the Cessna 208 were of high accuracy because of the WESCAM MX-15HDi camera that calculated the GPS position of the targeted object. The overall sampling error made was therefore considered to be small, in particular with regard to the large distance range at which tuna schools can be detected (see below).

\section{Strip and line transect modeling}

Two distinct approaches were applied to derive density and abundance estimates from the number of sighted tuna schools, known as strip and line transect approaches (Buckland 2001, Thomas et al. 2012). Both methods rely on the sighting frequency of investigated objects, in particular their perpendicular distance to the transect line. A related key assumption is that the detection probability is certain on the transect line but decreasing with increasing distance. In the strip transect approach, the (perpendicular) sighting distance frequency distribution (SDFD; Fig. 3) is truncated at a distance where the detection probability is still certain and thus constant (Fig. 1). The object density is then derived by:

$$
\hat{D}_{i}=\frac{n_{i}}{2 w L}
$$

where $\hat{D}_{i}$ is the density estimate (number per unit area) of survey $i$, and $n_{i}$ is the number of objects (tuna schools) detected during survey $i$, on a transect of length $L$ and within a distance $w$.

The line transect approach aims to estimate the detection probability per distance (detectability $P$ ) and thus to calculate the percentage of sighted and nonsighted objects. It thus follows an altered version of Eq. (1), that is:

$$
\hat{D}_{i}=\frac{n_{i}}{2 w L P}
$$

The detectability $P$, also known as observability or sightability (Pierce et al. 2012), is estimated by fitting a 'detection function' to the SDFD (Fig. 3) and may depend on other variables (e.g. school size). In theory, the shape of the SDFD and thus the detection function resembles that of a monotonically decreasing, reverse-sigmoidal curve, showing a shoulder under which detection remains almost certain and is unaffected by other variables (Buckland 2001). Again, in strip transect theory, the data is truncated to this shoulder area, and $w$ corresponds to the shoulder width. Due to the rather spiked shape of the 
SDFD, such a shoulder cannot be easily detected in the present dataset. Therefore, we selected 3 truncation levels $(1.85,2.8$ and $3.7 \mathrm{~km}$, corresponding to 1 , 1.5 and 2 nautical miles; Fig. 3) for which striptransect densities were calculated and compared. Higher truncation was not considered to avoid data omission and maintain the spatial representativeness. For line transects, data truncation is performed to exclude outliers, in particular secondary sightings, and thus to facilitate modeling. According to common practice, we discarded 5 to $10 \%$ of the largest distances, which correspond in the present study to a band width of 4.5 and $3.5 \mathrm{~km}$ (Buckland et al. 1993). Line transect analyses were conducted using the 'ddf' and 'dht' functions of the 'mrds' package (Laake et al. 2013) of the statistical language $R$ (R Core Team 2014). Two different key functions, the half normal and hazard rate, were applied in the modeling of the detection probability. As mentioned above, the detectability of objects might be affected by multiple factors. These factors can in turn affect the shape of the detection function and may provide a more reasonable fit when included as covariates in line transect modeling, which is known as multi-covariate distance sampling (MCDS; Marques \& Buckland 2004, Thomas et al. 2012). For instance, under higher sea state, more distant schools might be less detectable, causing a narrower shape of the detection function. In the present study, the number and combination (team) of observers on board as well as the sea state, the plane used and the school size were considered as possible covariates affecting the detectability of tuna schools. As an indicator for the sea state, 0.25 degree, daily sea surface wind speeds over the Mediterranean, derived from the NOAA Blended Sea Winds data set, were used (www.ncdc.noaa.gov/ oa/rsad/air-sea/seawinds.html). Daily average wind speeds in the study area were calculated, and in case of surveys before 2012, the average of the respective sub-area, west or east of $46.5^{\circ} \mathrm{E}$, were extracted. Absolute and Beaufort scale were also applied in the modeling for comparison.

Regarding the covariate school size, co-occurring schools with only 1 GPS record were treated as 1 sighted object for which the school size information was summarized. The treatment of the aggregation zones was more problematic, as only a few sighting positions referred to a large but 'uncountable' amount of tuna schools in an area of a few nautical miles. Due to their rarity and the fact that they could not be summarized by a single GPS position, these sightings could not be introduced in the line transect modeling and treated as the other sightings. Because aggrega-

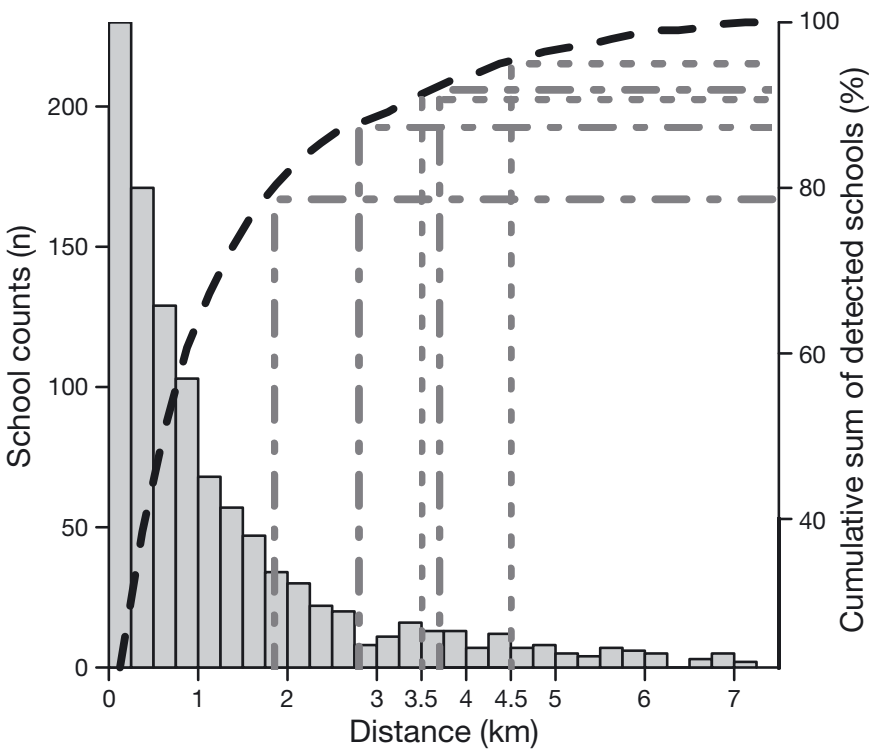

Fig. 3. Absolute frequencies and cumulated percentage (black line) of the number of schools being detected per perpendicular distance to the transect route. Dotted and dashdotted lines (grey) indicate the percentage of data included at the different truncation levels, used in the strip and line transect approaches, respectively

tion zones were large and much more easily detectable, it was assumed that they were always detected. As such, they were not modeled but were added directly to density estimates.

Line transect models were selected based on Akaike's information criterion (AIC) and further evaluated using goodness of fit tests ( $q-q$ plots, Cramervon Mises and Kolmogorov-Smirnov tests).

\section{Tuna densities in the GoL}

For both modeling approaches, school density estimates were derived for each school size class and each survey. In line transect modeling, this was achieved by running the 'dht' function on each survey and school size class separately. To obtain tuna density estimates in number of fish per surface area, the number of tunas per school is needed as a conversion factor. Since only jumping or near-surface individuals are seen by observers, the true number of tunas per school cannot be estimated from a plane. However, the total tuna number of tuna for the different school sizes might be reflected by the catch from purse seiners (PS) targeting free-swimming tuna schools in that area. To estimate school size, we therefore selected data of single PS sets from French PS that were operating in the GoL during the aerial survey season (August to October) in 2000 to 2007, 
assuming that a single PS set corresponds to a single school. A total number of 594 PS sets was finally retained. To identify different school size groups, a Gaussian mixture model was applied to the PS dataset, using the 'mixmodCluster' function from the $\mathrm{R}$ package 'Rmixmod' (Auder et al. 2014). Four modes were detected in accordance with the 4 school size classes considered in this study (Fig. 4). Each mode is described by a normal distribution whose variance is considered to correspond to the variability within the related school size class (Table 2). The number of tunas found in 1 aggregation zone, the largest considered school size, could thereby consist of $626.4 \pm$ 305.5 individuals. To account for the variability of a particular school size class, the total number of fish per school (size class) was not assigned to a fixed value, but was selected randomly (with replacement, $\mathrm{n}=1000$ ) from the corresponding size class distribution.

\section{Annual tuna densities in the GoL}

From survey estimates, the annual mean densities $\bar{D}$, of both tuna schools (school densities) and absolute tuna numbers (tuna densities), were approximated for the strip and line transect approaches as follows:

$$
\bar{D}=\frac{1}{r} \sum_{i=1}^{r} \hat{D}_{i}
$$

where $\hat{D}_{i}$ gives the previously calculated tuna school/ total tuna number density of survey $i$ of $r$ total replicates (number of surveys) in the year concerned. The associated variance $V(D)$ of yearly densities was defined as follows:

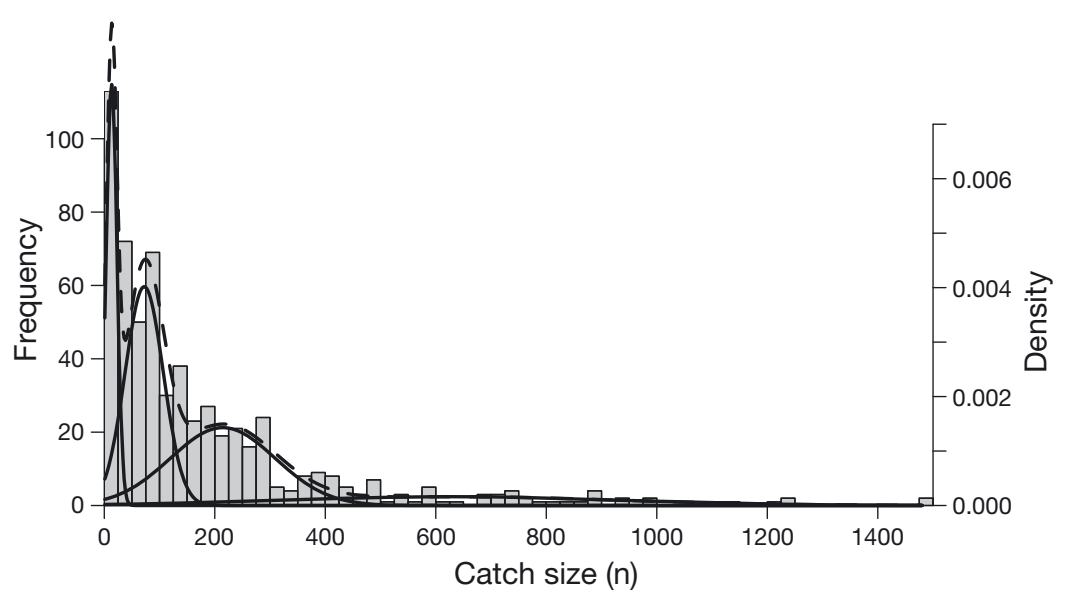

Fig. 4. Catch size of French purse seiners during August to October for 2000 to 2007, as well as fitted distributions of the Gaussian mixture model (solid lines) and their combined density (dashed line). The distributions are considered to correspond to size classes found during the aerial surveys
Table 2. Average number of tuna per size class $(\bar{x})$ and related standard deviation $(\sigma)$ estimated by the Gaussian mixture (Fig. 4)

\begin{tabular}{|lccc|}
\hline School size class & Mode & $\bar{x}$ & $\sigma$ \\
\hline Small & 1 & 13.3 & 9.6 \\
Medium & 2 & 72.3 & 34.7 \\
Large & 3 & 214.4 & 94.9 \\
Aggregation & 4 & 626.4 & 305.5 \\
\hline
\end{tabular}

$$
V(D)=\frac{1}{r(r-1)} \sum_{i=1}^{r}\left(\hat{D}_{i}-\bar{D}_{i}\right)^{2}
$$

\section{Spatial distribution of tuna schools}

As population size fluctuates, the habitat used by a species can also fluctuate (MacCall's theoretical basin model; MacCall 1990). We thus examined the spatial distribution of sighted tuna schools in the GoL to investigate whether the area used in the GoL has changed through time. Spatial densities were calculated from the number of sightings per year, weighted by the survey effort and the average of their respective size class (Table 2). To interpolate across sighted schools in the GoL, an axis-aligned bivariate normal kernel, given by the 'kde2d' function from the R package 'MASS', was applied (Venables \& Ripley 2002), using a bandwidth of 0.5 and on a square grid of $500 \times 500$ points (horizontal resolution: $6.7 \mathrm{~km}$ ). To facilitate comparison between years, annual density distributions were weighted by the respective annual density estimates obtained from the line transect approach at truncation level of $4.5 \mathrm{~km} \mathrm{(5 \% ).}$

\section{RESULTS}

We found a very consistent pattern between modeling approaches and density estimates in which the abundance index of juvenile ABFT derived from aerial surveys in the Gulf of Lions is 3- to 4 -fold higher over the recent period (2009-2012) than during the early 2000s (Figs. 5 \& 6). Using this dataset, the abundance estimates derived from the line transect theory was more stable and robust to the different hypotheses about the trunca- 

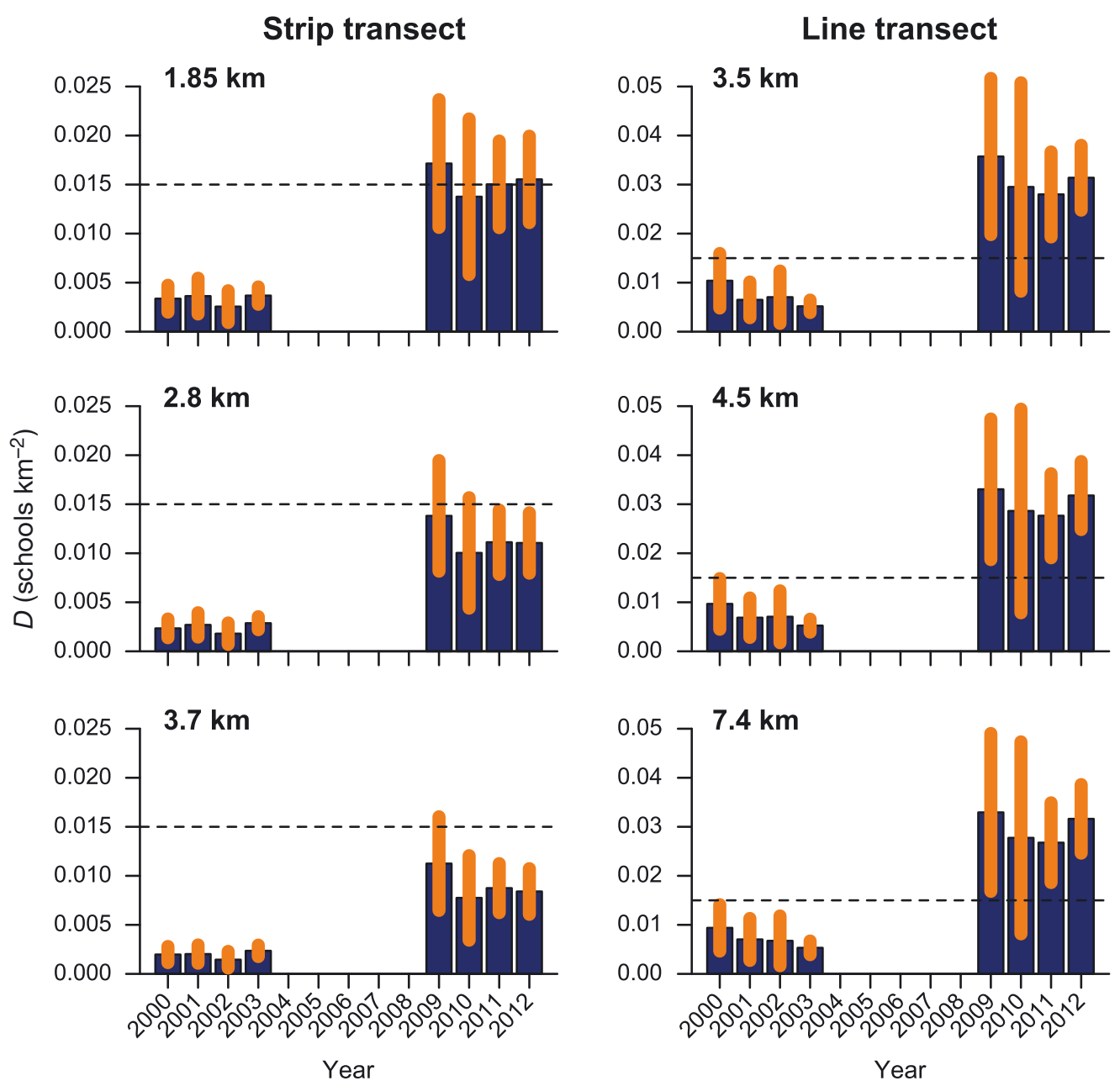

Fig. 5. School densities $(D)$ of tunas in the Gulf of Lions derived from the strip transect and line transect approaches. Each row corresponds to the results of different truncation levels $(1.85,2.8$ and $3.7 \mathrm{~km}$ for strip transects, 3.5, 4.5 and 7.4 (untruncated) $\mathrm{km}$ data for line transects). The variance per yearly estimate is indicated by orange bars. The density of $0.015 \mathrm{schools} \mathrm{km}^{-2}$ is marked by the dashed reference line

tion distances (Figs. 5 \& 6). This substantial increase in the abundance index is concurrent with a substantial increase in the spatial extent where ABFT juvenile have been observed in the Gulf of Lions (Fig. 7).

\section{Changes in school size}

Different school sizes were consistently sighted during each survey year (Fig. 8). The number of observed tuna schools of all size classes significantly increased since 2003. The sighting frequency per school size commonly decreased with increasing school size. Aggregation zones were not observed before 2009 and were most frequent in 2010. In the same year, small schools were much less frequent than in other survey years between 2009 and 2012. In the early survey years, remarkably high numbers of large schools were found in 2003.

\section{Detectability and line transect modeling}

Best model fits for each truncation level, selected using AIC, were obtained from the multiple-covariate approach based on a hazard rate key-function (Fig. S2 in the Supplement at www.int-res.com/ articles/suppl/m534p221_supp.pdf). Goodness-of-fit tests (Cramer-von Mises and Kolmogorov-Smirnov tests) performed well for all selected models $(\mathrm{p}>$ $0.05)$, with no significant deviation visible in the $q-q$ plots. Models with the hazard rate key-function generally performed better than those of the half-normal, as they could better reproduce the spiked SDFD. Best 


\section{Strip transect}
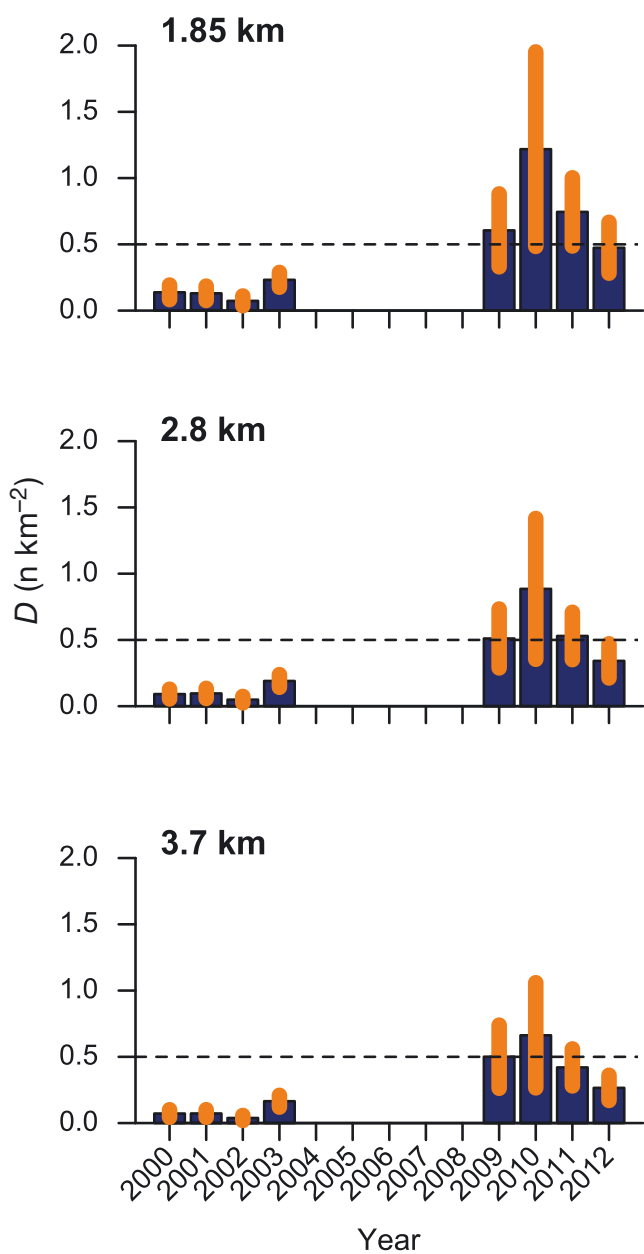

Line transect
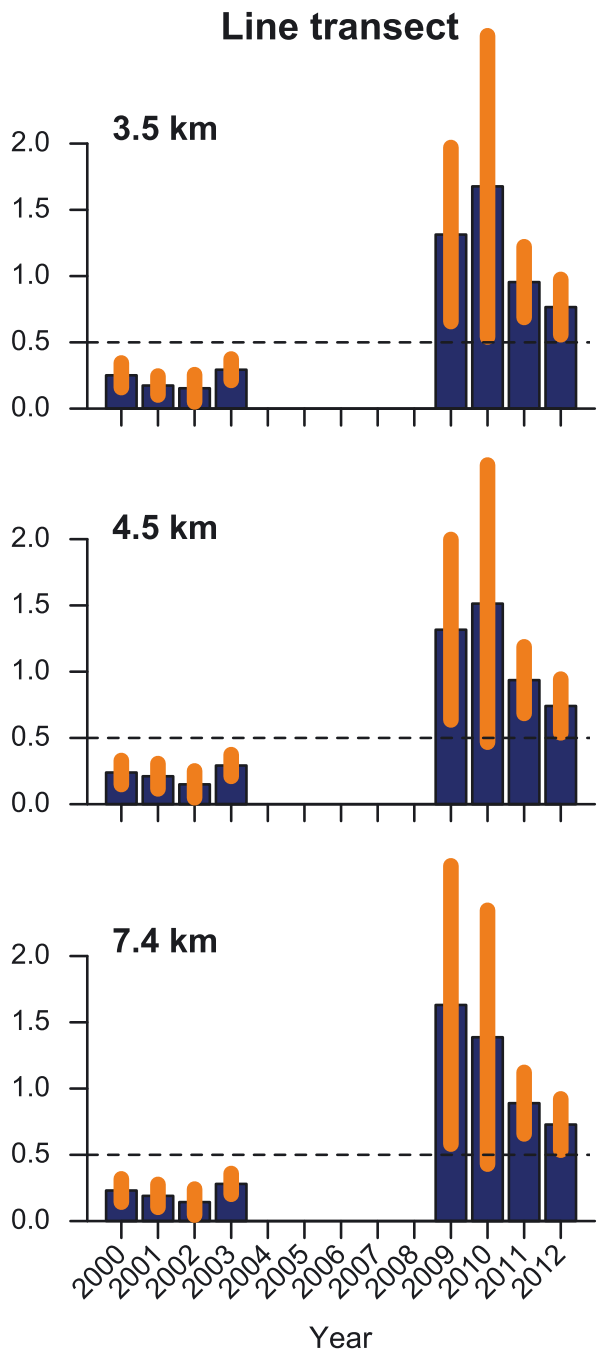

Fig. 6. Tuna densities $(D)$ in the Gulf of Lions derived from the strip transect and line transect approaches. Each row corresponds to the results of different truncation levels $(1.85,2.8$ and $3.7 \mathrm{~km}$ for strip transects, 3.5, 4.5 and 7.4 (untruncated) km data for line transects). The variance per yearly estimate is indicated by orange bars. The density of 0.5 tunas $\mathrm{km}^{-2}$ is marked by the dashed reference line

fits across all truncation levels indicated significant effects on the detectability by the observer team, school size and the sea state (Beaufort scale). The observer team effect is considered as an interaction of observer and type of aircraft and is further described in Table S1 in the Supplement. Sea state and school size had opposing effects on detectability, as expected. Larger swell and whitecaps caused a stronger decline in detectability with distance, while schools were easier to spot as their size increased.

\section{School and tuna densities in the GoL}

Estimated school densities indicated a very consistent and substantial increase in abundance irrespective of the modeling approach (strip or line transect; Fig. 5). Estimates up until 2003 were generally 3- to 4 -fold lower than those from 2009 onwards. However, line transect estimates were approximately twice as high as that of strip transects and appeared to be more stable across the different truncation levels

Fig. 7. Spatial kernel densities of total tuna counts in the Gulf of Lions per survey year weighted by the corresponding annual survey effort and tuna density estimates obtained from the line transect approach at truncation level of $4.5 \mathrm{~km}(5 \%)$. Sighting positions of tuna schools are illustrated by black dots. The white dashed lines give the 200 and $2000 \mathrm{~m}$ isobaths, indicating the continental shelf break of the Gulf of Lions 

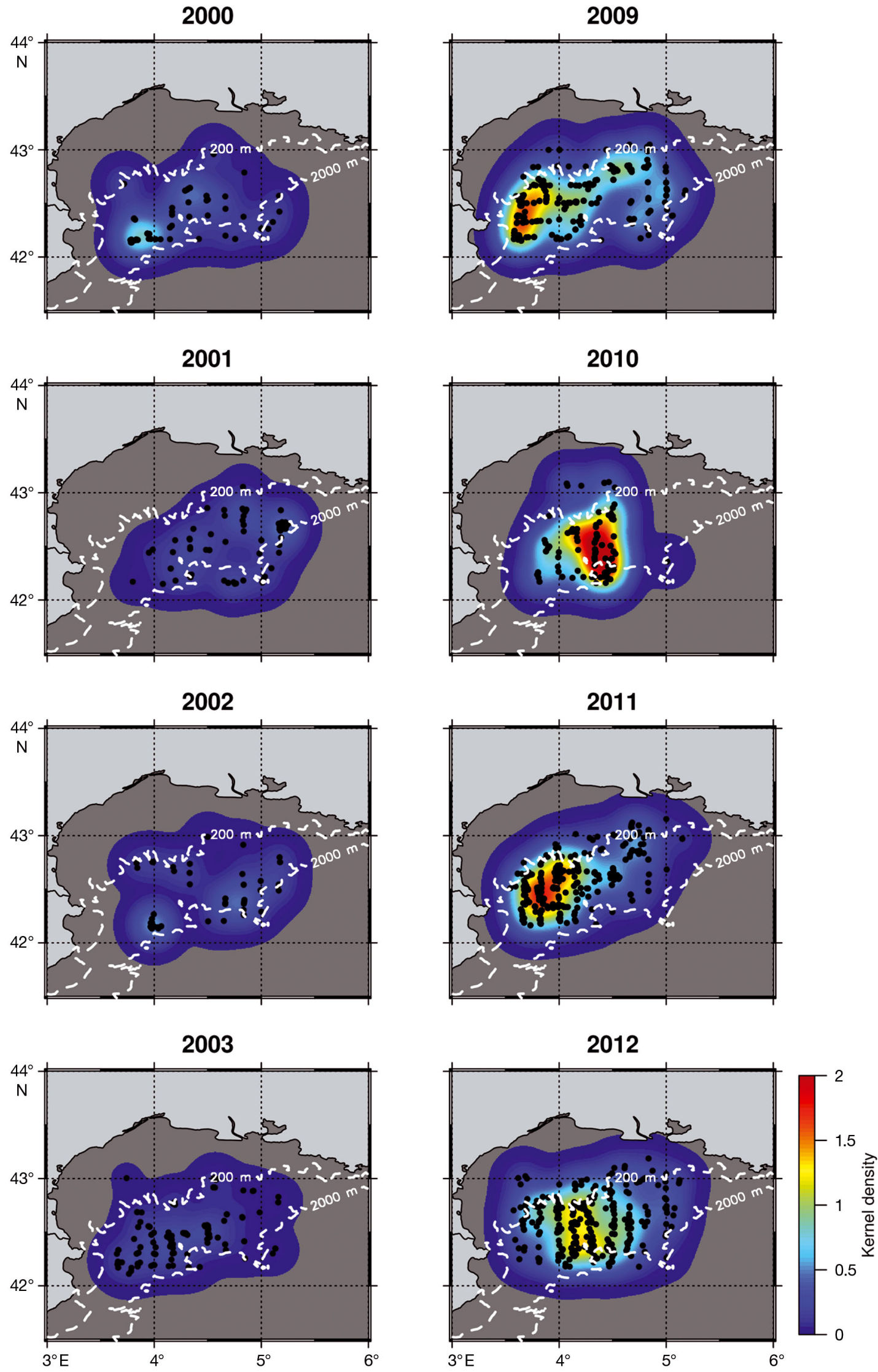


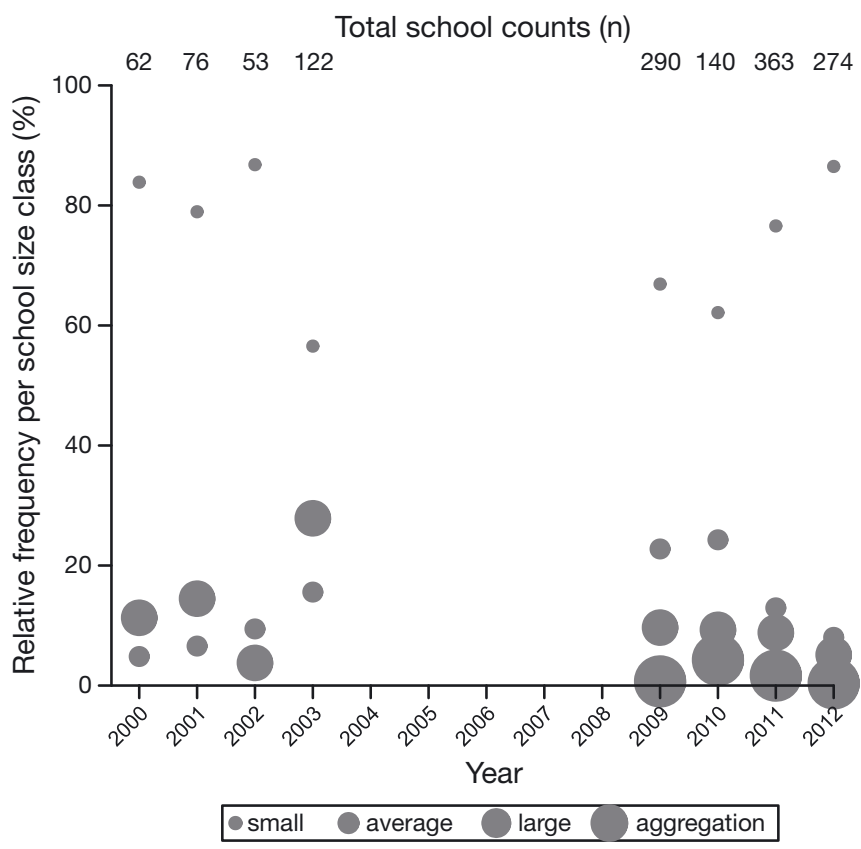

Fig. 8. Relative frequencies of different school size classes during each survey year

applied. By contrast, school densities obtained by the strip transect approach commonly decreased with lower truncation. Accordingly, their range was 0.0026-0.017 and 0.0018-0.014 schools $\mathrm{km}^{-2}$ at a truncation level of 1.852 and $2.8 \mathrm{~km} \mathrm{(22 \%} \mathrm{and} 12.8 \%$ data truncation), respectively.

Tuna densities showed a similar increase from the early 2000s to the period 2009 to 2012, but were less stable in the latter period. Similarly, strip transect results were significantly lower than those obtained from the line transect approach. Both approaches indicated a high tuna density for 2010, coinciding with the highest number of observed aggregation zones during the entire survey years (Fig. 5).

\section{Spatial distribution of tuna schools}

Spatial kernel densities of juvenile ABFT showed a marked increase during recent survey years as opposed to those from 2000 to 2003 (Fig. 7). Considering all survey years, tuna densities were generally highest in the continental shelf break area, particularly in the central and western part of this region. Accordingly, a clear center could be observed in 2009 and 2010. In contrast to the early survey years when the distribution of tunas was largely restricted to the slope area, since 2009 the distribution of tunas was much larger and tunas were frequently observed on the shelf area. This is also apparent from the fre- quency at which tuna schools were sighted, at different depth contours, when weighted by the survey effort (Fig. S3 in the Supplement). Note that in 2010, flights and thus sightings were limited to the western region of the survey area due to unsuitable weather conditions (Fig. S4).

\section{DISCUSSION}

In the present study, we used aerial surveys to estimate the abundance of juvenile ABFT in the Northwestern Mediterranean Sea. Two statistical methods were applied to derive abundance estimates from sighted tuna schools: strip and line transect approaches. The results obtained from both approaches showed large similarities across the entire time series of both school and tuna densities. In particular, they indicate a significant increase in juvenile ABFT abundance between the 2 time periods, i.e. 2000-2003 and 2009-2012. School and tuna densities remain high in the subsequent years that are also marked by high intra-annual variability (i.e. high standard deviation in Figs. 5 \& 6). Differences in school and tuna densities are based on year-to-year variations in school size frequencies. In this regard, the occurrence of aggregation zones during the most recent years likely reflects the observed increase in juvenile ABFT abundance from 2003 to 2009. Apart from this observation, sighting frequencies of small schools increased during the most recent years (2011-2012) in relation to medium and large schools, suggesting a decrease in tuna densities while school densities remain stable. However, with regard to the higher variability of 2009-2010 tuna density estimates, it remains unclear whether this could indicate a trend.

\section{Strip vs. line transect modeling}

In general, estimates of the line transect approach were systematically higher and more stable across the different truncation levels, indicating superior robustness. The lower estimates from the strip transect approach suggest that some tuna schools were missed within the applied strip widths. This is also shown by a rapid decrease in the frequency of school sightings with increasing distance. However, a further reduction of the strip width would not only impair the spatial representativeness of the survey but also result in the omission of a large number of sightings. The latter would artificially introduce surveys with zero sightings, resulting in the distortion of 
annual averaged density estimates. These problems demonstrate major constraints in the application of the basic strip transect theory to the presented visual-based aerial surveys. An adaptive strip transect approach in which the strip width is not set to a fixed value but is a function of the major factors influencing detectability (e.g. school size and sea state; Fig. 1) may improve density estimates but would require further modeling efforts. This would remove one of the main advantages of the strip transect approach, i.e. its simplicity. In this context, the principle advantage of the line transect approach is its ability to incorporate detections over a large sighting distance, thereby correcting for potential effects on detectability. This further explains the slight differences in the trends of tuna density estimates between both approaches, as school size frequencies are altered during the line transect modeling, considering school size as a covariate.

\section{Effects of tuna behavior on abundance estimates}

Differences in the temporal development of school and tuna densities are driven by the changes in the school size distribution and concern mainly the weighting of the years 2010 and 2012, which were marked by a high number of tuna aggregation zones and small schools, respectively. Accordingly, within the 2009-2012 period, school densities are lowest in 2010, while the corresponding tuna densities are of the same level or even greater than those of surrounding years. By contrast, the opposite effect was found for 2012: high school densities (mainly from the line transect approach) but lower tuna densities. Generally, tuna densities appear to be more reliable as they account for differences in school size. However, more precise information on school size is needed to improve the accuracy of density estimates. In the present method, school size is first classified during the surveys according to the observed size of the water disturbance created by tunas, using a semiquantitative approach, and is then expressed in numbers of fish, using information from PS catch data. This may not fully reflect the actual school size because the size of the observed water disturbance likely depends on multiple factors besides tuna school size, e.g. the temporal dynamics of the intensity of the feeding event or the vigor of the feeding activity (Fig. 1). In addition, the estimated number of fish per school can contain large variations, especially for large schools, as indicated by the evaluated PS dataset. Simultaneously conducted acoustic sur- veys could be used to detect and estimate the biomass of pelagic fish below the water surface and its dependency on feeding dynamics (Weber et al. 2013). In theory, such knowledge could also be gained by airborne LIDAR (light detection and ranging). However, light-weight and power-efficient LIDAR systems for tuna detection that further allow real time processing are still under development (Schoen \& Sibert 1996, Churnside et al. 1998, Cowling et al. 2002).

Another compounding factor is that, unlike the case of marine mammals, surfacing is not an obligatory behavior of tunas, although ABFT is an epipelagic species that preferentially occupies surface and sub-surface waters (Fromentin \& Powers 2005, Walli et al. 2009). A related problem concerns the common occurrence of surveys with no sightings, which represent a major source of the variability in annual abundance estimates. In fact, ABFT often disappear only to reemerge soon thereafter, usually within a couple of days, indicating that they remained within or, close to, the survey zone. Therefore, it is necessary to replicate the survey several times during the season to avoid any bias due to changes in tuna behavior (Cowling et al. 2002, Bonhommeau et al. 2010). Such short-term changes in the distribution of tunas are indeed likely caused by changes of environmental conditions. For example, strong continental winds, known as Tramontane and Mistral, can cause the temperature of the surface layer in the GoL to drop by up to $5^{\circ} \mathrm{C}$ within $1 \mathrm{~d}$ and produce local upwellings (Millot 1979). The wind-induced disturbance of the epipelagic zone may affect the vertical distribution of zooplankton (Incze et al. 2001) and thus the foraging behavior of small pelagic fish, the main prey of juvenile ABFT in the GoL. Accordingly, ABFT may adapt their feeding mode and their vertical distribution (Fig. 1). Future studies should therefore aim to assess the changes in the vertical and horizontal distribution patterns of ABFT in relation to prevailing environmental conditions. Regional archival tagging data, as presented by Fromentin \& Lopuszanski (2014), can help to fulfill this task as shown in other studies (Cowling et al. 2002, Newlands et al. 2006, Hobday et al. 2009). An important factor could represent changes in the mesoscale eddy and frontal activity that are known to attract both tunas and their prey (Fiedler \& Bernard 1987, Royer et al. 2004, Schick et al. 2004). Mesoscale activity is high in the GoL, especially along the continental slope (André et al. 2009), an area that also constitutes an important fishing ground for small pelagic fish (Saraux et al. 2014). Tuna kernel densities presented here are 
highest in this region, while sightings of tuna schools on the continental shelf are less common. These findings are in accordance with results of early research flights in 1989 and commercial tuna spotter data of 1996 and 1997 from the same region (Petit et al. 1990, Liorzou 2001).

\section{Importance of aerial surveys for tuna management}

The presented results demonstrate that aerial surveys, which are more commonly used to monitor marine mammal populations, are also suitable for ABFT in the Mediterranean. Marine mammals, such as striped dolphins, fin and sperm whales, were also frequently observed during the surveys. Combined multi-species surveys could thus provide an opportunity for collaboration and reduce total survey effort and costs for both species groups. Additionally, larger areas could be covered. Aerial surveys of marine mammals and sea turtle abundance have already been conducted in other nursery areas of ABFT, such as in the Gulf of Genoa, the Adriatic and the Balearic Sea, and provided crucial knowledge for the conservation of these endangered species (Carreras et al. 2004, Forcada et al. 2004, Fortuna et al. 2011, Lauriano et al. 2011, Panigada et al. 2011). While the presented time series is long enough to be used for stock assessment, an increase in its spatial representativeness would be needed to assess recruitment trends of eastern ABFT. This does not concern the GoL feeding ground as its spatial coverage is considered sufficient with aerial surveys being carried out from the coastline to high depth areas (>2000 m). However, additional aerial surveys on other key nursery areas of ABFT, as mentioned above, would greatly help improve the representativeness and hence the index of juvenile ABFT abundance based on aerial surveys (ICCAT 2012). This is of particular importance since changes in the index can also be related to changes in the distribution of schools due to environmental forcing or ecological changes and thus be unrelated to management regulations.

The positive trend observed in juvenile ABFT abundance in the GoL is consistent with stock assessment outputs (ICCAT 2013). Moreover, large tuna school aggregation zones have been observed since 2009, which were not present in the previous years. These results likely reflect the success of the ABFT rebuilding plan that led, among other things, to a drastic decline of the catch in the surveyed area (Fromentin et al. 2014). To date, ABFT stock assessment relies primarily on fisheries-dependent infor- mation (i.e. CPUE, which has several limitations (ICCAT 2013, Fromentin et al. 2014). Such information is strongly affected by changes in fishery strategy and management regulations. The implementation of the 2007 ABFT rebuilding plan had such effects (Fromentin et al. 2014). The increase in the minimum landing size together with a drastic reduction of the total allowable catch and the fishing season have strongly impacted all the fisheries that formerly provided CPUE indices for ABFT assessment (ICCAT 2013). As such, while the ABFT rebuilding plan has very positive outcomes in terms of the stock size, it also impairs the ability of CPUE indices to track changes in ABFT abundance. The index of abundance presented here does not suffer these constraints and thus offers a critical opportunity to provide a fishery-independent survey that would facilitate the tracking of changes in ABFT abundance.

It is worth noting that ICCAT has recently initiated an Atlantic-wide research program to develop fishery-independent abundance indices for ABFT to improve stock assessment (ICCAT 2012). In current pilot studies, aerial surveys on mature ABFT were conducted in several key Mediterranean breeding areas. Conservation of the southern bluefin tuna is even more advanced, as aerial surveys constitute one of the 2 key sources of information for the evaluation of the recently implemented management strategy for the southern bluefin tuna stock (Rich et al. 2012). Undoubtedly, aerial surveys are a promising tool to monitor large pelagic fish abundance and follow management measure efficiency, but their value critically relies on long-term coverage and thus necessitates a continuous and substantial effort that national or international programs can hardly guarantee. The implementation of a scientific quota, as suggested by Fromentin et al. (2014), could represent a way forward that would allow the development of long-term scientific surveys.

Acknowledgments. The authors thank the different pilots that have participated in the aerial surveys. The aerial surveys were first funded by the EU project STROMBOLI (2000-2002), then by Ifremer (2003) and the French administration (convention IFREMER-DPMA, 2009 onward). This study was supported by a PhD grant from France Filière Pêche (N LM-2012-144) and IFREMER (fellowship contract to R.K.B.).

\section{LITERATURE CITED}

Alves MDdO, Schwamborn R, Borges JaCG, Marmontel M, Costa AF, Schettini CAF, de Araújo ME (2013) Aerial survey of manatees, dolphins and sea turtles off north- 
eastern Brazil: correlations with coastal features and human activities. Biol Conserv 161:91-100

André G, Garreau P, Fraunie P (2009) Mesoscale slope current variability in the Gulf of Lions. Interpretation of insitu measurements using a three-dimensional model. Cont Shelf Res 29:407-423

Andriolo A, Martins CCA, Engel M, Pizzomo JL and others (2006) The first aerial survey to estimate abundance of humpback whales (Megaptera movaeangliae) in the breeding ground off Brazil (Breeding Stock A). J Cetacean Res Manag 8:307-311

Auder B, Lebret R, Iovleff S, Langrognet F (2014). Rmixmod: an interface for MIXMOD. http://cran.r-project.org/ package $=$ Rmixmod

Beavers SC, Ramsey FL (1998) Detectability analysis in transect surveys. J Wildl Manag 62:948-957

Bonhommeau S, Farrugio H, Poisson F, Fromentin JM (2010) Aerial surveys of bluefin tuna in the western Mediterranean Sea: retrospective, prospective, perspectives. Col Vol Sci Pap ICCAT 65:801-811

Buckland ST (2001) Introduction to distance sampling: estimating abundance of biological populations. Oxford University Press, Oxford

Buckland ST, Anderson DR, Burnham KP, Laake JL (eds) (1993) Distance sampling: estimating abundance of biological populations. Chapman \& Hall, London

Carreras C, Cardona L, Aguilar A (2004) Incidental catch of the loggerhead turtle Caretta caretta off the Balearic Islands (western Mediterranean). Biol Conserv 117:321-329

Churnside J, Wilson JJ, Oliver CW (1998) Evaluation of the capability of the experimental oceanographic fisheries lidar (FLOE) for tuna detection in the eastern tropical Pacific. NOAA Tech Memo ERL ETL-287. Environmental Technology Laboratory, Boulder, CO

Cowling A, Hobday A, Gunn J (2002) Development of a fishery independent index of abundance for juvenile southern bluefin tuna and improved fishery independent estimates of southern bluefin tuna recruitment through integration of environmental, archival tag and aerial survey data November 2002. Final report. CSIRO Marine Research, Hobart

Eveson P, Farley J, Bravington M (2012) The aerial survey index of abundance: updated analysis methods and results for the 2011/12 fishing season. CCSBT-ESC/ 1208/16, 17th meeting of the Scientific Committee, Commission for the Conservation of Southern Bluefin Tuna, 27-31 August 2012, Tokyo

Farrugio H (1977) Données préliminaires sur la pêche au thon rouge au filet tournant en Méditerranée Française. Col Vol Sci Pap ICCAT 6:245-252

> Fiedler PC, Bernard HJ (1987) Tuna aggregation and feeding near fronts observed in satellite imagery. Cont Shelf Res 7:871-881

Forcada J, Gazo M, Aguilar A, Gonzalvo J, FernandezContreras M (2004) Bottlenose dolphin abundance in the NW Mediterranean: addressing heterogeneity in distribution. Mar Ecol Prog Ser 275:275-287

Fortuna C, Holcer D, Filidei E Jr, Donovan G, Tunesi L (2011) First cetacean aerial survey in the Adriatic sea: summer 2010. In: Seventh Meet ACCOBAMS Sci Committee. ACCOBAMS-SC7/2011/Doc06, 29-31 March 2011, Monaco

Fromentin JM, Lopuszanski D (2014) Migration, residency, and homing of bluefin tuna in the western Mediterranean Sea. ICES J Mar Sci 71:510-518
Fromentin JM, Powers JE (2005) Atlantic bluefin tuna: population dynamics, ecology, fisheries and management. Fish Fish 6:281-306

Fromentin JM, Bonhommeau S, Brisset B (2013) Update of the index of abundance of juvenile bluefin tuna in the western Mediterranean Sea until 2011. Col Vol Sci Pap ICCAT 69:454-461

Fromentin JM, Bonhommeau S, Arrizabalaga H, Kell LT (2014) The spectre of uncertainty in management of exploited fish stocks: the illustrative case of Atlantic bluefin tuna. Mar Policy 47:8-14

Fujioka K, Hobday AJ, Kawabe R, Miyashita K, Honda K, Itoh T, Takao Y (2010) Interannual variation in summer habitat utilization by juvenile southern bluefin tuna (Thunnus maccoyii) in southern Western Australia. Fish Oceanogr 19:183-195

Hobday A, Kawabe R, Takao Y, Miyashita K, Itoh T (2009) Correction factors derived from acoustic tag data for a juvenile southern bluefin tuna abundance index in southern Western Australia. In: Nielsen JL, Arrizabalaga H, Fragoso N, Hobday A, Lutcavage M, Sibert J (eds) Reviews: methods and technologies in fish biology and fisheries: tagging and tracking of marine animals with electronic devices. Springer, London, p 405-422

Hoggard W (1995) Aerial survey applications for assessing bluefin tuna abundance, distribution, and age structure in the northwest Atlantic: a pilot study. Col Vol Sci Pap ICCAT 45:151-154

ICCAT (2006) Recommendation by ICCAT to establish a multi-annual recovery plan for bluefin tuna in the Eastern Atlantic and Mediterranean. Recommendation 06-05. ICCAT, Madrid

ICCAT (2012) 2011 GBYP workshops on aerial surveys, and operational meetings on biological sampling and on tagging of bluefin tuna (Madrid, Spain, February 14-18, 2011). Collect Vol Sci Pap ICCAT 68:1-65

ICCAT (2013) Report of the 2012 Atlantic bluefin tuna stock assessment session. Col Vol Sci Pap ICCAT 69:1-198

Incze L, Hebert D, Wolff N, Oakey N, Dye D (2001) Changes in copepod distributions associated with increased turbulence from wind stress. Mar Ecol Prog Ser 213:229-240

Ingram GJ, Alemany F, Alvarez D, Garcia A (2013) Development of indices of larval bluefin tuna (Thunnus thynnus) in the western Mediterranean Sea. Col Vol Sci Pap ICCAT 69:1057-1076

> Josse E, Dagorn L, Bertrand A (2000) Typology and behaviour of tuna aggregations around fish aggregating devices from acoustic surveys in French Polynesia. Aquat Living Resour 13:183-192

Laake J, Borchers D, Thomas L, Miller D, Bishop J (2013) MRDS: mark-recapture distance sampling (mrds). R package version 2.0.5, http://CRAN.R-project.org/package $=\mathrm{mrds}$

Lauriano G, Panigada S, Casale P, Pierantonio N, Donovan GP (2011) Aerial survey abundance estimates of the loggerhead sea turtle Caretta caretta in the Pelagos Sanctuary, northwestern Mediterranean Sea. Mar Ecol Prog Ser 437:291-302

Leroy B, Nicol S, Lewis A, Hampton J, Kolody D, Caillot S, Hoyle S (2015) Lessons learned from implementing three, large-scale tuna tagging programmes in the western and central Pacific Ocean. Fish Res 163:23-33

Liorzou B (2001) Effect of spotter aircraft on CPUE indices and feasability study to obtain new abundance indices. In: BFTMED—Major improvements in our knowledge of 
Eastern Atlantic Bluefin Tuna in the Mediterranean (Fisheries, Statistics and Biology), Final Report of the EU Project 97/029. European Community-DG XIV, Brussels, p 124-131

Lutcavage M, Kraus S (1997) Aerial survey of giant bluefin tuna, Thunnus thynnus, in the Great Bahama Bank, Straits of Florida, 1995. Fish Bull 95:300-310

Lutcavage M, Newlands N (1999) A strategic framework for fishery-independent aerial assessment of bluefin tuna. Col Vol Sci Pap ICCAT 49:400-402

MacCall AD (1990) Dynamic geography of marine fish populations. Washington University Press, Seattle, WA

Marques FFC, Buckland ST (2004) Covariate models for the detection function. In: Buckland ST, Anderson DR, Burnham KP, Laake JL, Borchers DL, Thomas L (eds) Advanced distance sampling. Oxford University Press, Oxford, p 31-47

Marques TA, Andersen M, Christensen-Dalsgaard S, Belikov S and others (2006) The use of global positioning systems to record distances in a helicopter line-transect survey. Wildl Soc Bull 34:759-763

Millot C (1979) Wind induced upwellings in the Gulf of Lions. Oceanol Acta 2:261-274

Natale AD (2011) ICCAT GBYP. Atlantic-wide Bluefin Tuna Research Programme 2010. GBYP Coordinator Detailed Activity Report for 2009-2010. Col Vol Sci Pap ICCAT 66: 995-1009

Newlands NK, Lutcavage ME, Pitcher TJ (2006) Atlantic bluefin tuna in the Gulf of Maine, I: estimation of seasonal abundance accounting for movement, school and school-aggregation behaviour. Environ Biol Fishes 77: 177-195

Panigada S, Lauriano G, Burt L, Pierantonio N, Donovan G (2011) Monitoring winter and summer abundance of cetaceans in the Pelagos Sanctuary (northwestern Mediterranean Sea) through aerial surveys. PLoS ONE 6: e22878

Petit M, Stretta J, Farrugio H, Wadsworth A (1990) HAREM (Halieutique et radar, Expérimentation en Méditerranée). Potentialités du radar SAR en halieutique. Application à la pêche thonière de surface et à la pêche artisanale. Collection Etudes thèses. ORSTOM, Paris

Pierce BL, Lopez RR, Silvy NJ (2012) Estimating animal abundance. The wildlife techniques manual, 7 th edn.

Editorial responsibility: Konstantinos Stergiou,

Thessaloniki, Greece
Johns Hopkins University Press, Baltimore, MD, p 284-310

Polacheck T, Pikitch E, Lo N (1998) Evaluation and recommendations for the use of aerial surveys in the assessment of Atlantic bluefin tuna. Col Vol Sci Pap ICCAT 48:61-78

R Core Team (2014) R: a language and environment for statistical computing. R Foundation for Statistical Computing, Vienna

Rich H, Preece A, Davies C (2012) Developing a management procedure based recovery plan for southern bluefin tuna, final report FRDC project 2011/034. CSIRO Marine \& Atmospheric Research, Hobart

Royer F, Fromentin JM, Gaspar P (2004) Association between bluefin tuna schools and oceanic features in the western Mediterranean. Mar Ecol Prog Ser 269:249-263

Saraux C, Fromentin JM, Bigot JL, Bourdeix JH and others (2014) Spatial structure and distribution of small pelagic fish in the Northwestern Mediterranean Sea. PLoS ONE 9:e111211

Schick RS, Goldstein J, Lutcavage ME (2004) Bluefin tuna (Thunnus thynnus) distribution in relation to sea surface temperature fronts in the Gulf of Maine (1994-96). Fish Oceanogr 13:225-238

Schoen C, Sibert J (1996) Feasibility of dual mode lidar for pelagic fish surveys. SOEST 96-02, IIMAR Contribution 96601

Scott JM, Flittner GA (1972) Behavior of bluefin tuna schools in the eastern north Pacific Ocean as inferred from fishermen's logbooks. Fish Bull 70:915-927

Thomas L, Buckland ST, Burnham KP, Anderson DR, Laake JL, Borchers DL, Strindberg S (2012) Distance sampling. In: El-Shaarawi AH, Piegorsch W (eds) Encyclopedia of environmetrics, 2nd edn. John Wiley \& Sons, Chichester, p 687-697

Venables WN, Ripley BD (2002) Modern applied statistics with S. Statistics and computing, 4th edn. Springer, New York, NY

> Walli A, Teo SLH, Boustany A, Farwell CJ and others (2009) Seasonal movements, aggregations and diving behavior of Atlantic bluefin tuna (Thunnus thynnus) revealed with archival tags. PLoS ONE 4:e6151

- Weber TC, Lutcavage ME, Schroth-Miller ML (2013) Near resonance acoustic scattering from organized schools of juvenile Atlantic bluefin tuna (Thunnus thynnus). J Acoust Soc Am 133:3802-3812

Submitted: October 28, 2014; Accepted: June 11, 2015 Proofs received from author(s): August 20, 2015 